University of Montana

ScholarWorks at University of Montana

6-2005

\title{
Linking Patterns and Processes in Alpine Plant Communities: a Global Study
}

Zaal Kikvidze

Francisco I. Pugnaire

Robin W. Brooker

Philippe Choler

Christopher J. Lortie

See next page for additional authors

Follow this and additional works at: https://scholarworks.umt.edu/biosci_pubs

Part of the Biology Commons

Let us know how access to this document benefits you.

\section{Recommended Citation}

Kikvidze, Zaal; Pugnaire, Francisco I.; Brooker, Robin W.; Choler, Philippe; Lortie, Christopher J.; Michalet, Richard; and Callaway, Ragan M., "Linking Patterns and Processes in Alpine Plant Communities: a Global Study" (2005). Biological Sciences Faculty Publications. 309.

https://scholarworks.umt.edu/biosci_pubs/309

This Article is brought to you for free and open access by the Biological Sciences at ScholarWorks at University of Montana. It has been accepted for inclusion in Biological Sciences Faculty Publications by an authorized administrator of ScholarWorks at University of Montana. For more information, please contact

scholarworks@mso.umt.edu. 


\section{Authors}

Zaal Kikvidze, Francisco I. Pugnaire, Robin W. Brooker, Philippe Choler, Christopher J. Lortie, Richard Michalet, and Ragan M. Callaway 


\title{
REPORTS
}

Ecology, 86(6), 2005, pp. 1395-1400

(C) 2005 by the Ecological Society of America

\section{LINKING PATTERNS AND PROCESSES IN ALPINE PLANT COMMUNITIES: A GLOBAL STUDY}

\author{
Zaal Kikvidze, ${ }^{1,2,8}$ Francisco I. Pugnaire, ${ }^{1}$ Robin W. Brooker, ${ }^{3}$ Philippe Choler,${ }^{4}$ \\ Christopher J. Lortie, ${ }^{5}$ Richard Michalet, ${ }^{6}$ and Ragan M. Callaway ${ }^{7}$ \\ ${ }^{1}$ Estación Experimental de Zonas Áridas, Consejo Superior de Investigaciones Cientificas, General Segura 1, \\ 04001 Almería, Spain \\ ${ }^{2}$ Institute of Botany of the Georgian Academy of Sciences, Kojori Road 1, Tbilisi, 380007, Georgia \\ ${ }^{3}$ Centre for Ecology and Hydrology, Banchory Research Station, Hill of Brathens, Banchory, \\ Aberdeenshire, AB31 4BY, UK \\ ${ }^{4}$ Station Alpine du Lautaret et Laboratoire d'Ecologie Alpine UMR CNRS UJF 5553, Université Joseph Fourier, Grenoble, \\ BP 53, 38041 Grenoble cedex, France \\ ${ }^{5}$ Natural Resources and Environmental Sciences, University of Nevada, 1000 Valley Road, Reno, Nevada 89512 USA \\ ${ }^{6}$ UMR INRA 1202 BIOGECO, Equipe Écologie des Communautés, Université Bordeaux 1, Avenue des Facultés, \\ 33405 Talence cedex, France \\ ${ }^{7}$ Division of Biological Sciences, University of Montana, Missoula, Montana 59818 USA
}

\begin{abstract}
Predictable relationships among patterns, processes, and properties of plant communities are crucial for developing meaningful conceptual models in community ecology. We studied such relationships in 18 plant communities spread throughout nine Northern Hemisphere high-mountain subalpine and alpine meadow systems and found linear and curvilinear correlative links among temperature, precipitation, productivity, plant interactions, spatial pattern, and richness. We found that sites with comparatively mild climates have greater plant biomass, and at these sites strong competition corresponds with overdispersed distribution of plants, reducing intraspecific patchiness and in turn increasing local richness. Sites with cold climates have little biomass, and at these sites a high proportion of species benefit from strong facilitative effects of neighbors, leading to an aggregated distribution of plants. Sites with intermediate, or relatively moderate climates are intermediate in biomass, and at these sites interactions are weak (or competition may be counterbalanced by facilitation), corresponding with a nearly random distribution of plants. At these sites species richness is lower than average. We propose that the relationship between interspecific spatial pattern and community richness reflects niche differentiation and/or construction, which allows for the coexistence of more species than would be possible with random, unstructured spatial distributions. Discovering the mechanisms that drive the relationships described here would further link functional and structural components of plant communities and enhance the predictive capability of community ecology.
\end{abstract}

Key words: Alpine systems; climate change; competition; environmental stress; facilitation; plant interactions; precipitation; productivity; spatial pattern; species diversity; temperature.

\section{INTRODUCTION}

There is an acute need for ecological experiments at broad geographical scales in order to understand the importance of processes that structure plant communities, and to predict the consequences of global change (Gaston and Blackburn 2000, Lawton 2000). There are many studies that have examined links between a limited selection of patterns and processes in communities, but as far as we are aware there have been no attempts

Manuscript received 20 December 2004; accepted 21 December 2004. Corresponding Editor: J. S. Brewer.

${ }^{8}$ E-mail: zaal@eeza.csic.es to simultaneously search for relationships among a large suite of community properties. The separate conceptual venues in community ecology have led to strong, but conceptually isolated, advances in community ecology (Tilman et al. 2001, McKane et al. 2002, Bruno et al. 2003, Lortie et al. 2004). For example, Grime (2001) based his conceptual theory for community organization on a search for a consistent relationship between competition and productivity. Independently, others have attempted to link the relative importance of facilitative and competitive interactions to abiotic stress and community productivity (Bertness and Callaway 1994, Callaway et al. 2002, Bruno et al. 
TABle 1. Descriptors for the 18 Northern Hemisphere alpine (high) and subalpine (low) study sites.

\begin{tabular}{llcrrrr}
\hline \hline \multicolumn{1}{c}{ Site location } & Site & $\begin{array}{c}\text { Latitude } \\
\left({ }^{\circ}\right)\end{array}$ & $\begin{array}{c}\text { Longitude } \\
\left({ }^{\circ}\right)\end{array}$ & $\begin{array}{c}\text { Elevation } \\
(\mathrm{m}) \dagger\end{array}$ & Aspect & $\begin{array}{c}\text { Slope } \\
\left({ }^{\circ}\right)\end{array}$ \\
\hline Alaska & High & 68.1 & 211 & 1400 & $\mathrm{E}$ & 15 \\
Alps & Low & 68.1 & 211 & 800 & flat & 0 \\
& High & 44.54 & 6.39 & 2900 & $\mathrm{SW}$ & 30 \\
Beartooth Mountains & Low & 44.54 & 6.39 & 2100 & flat & 0 \\
& High & 45.1 & 250.8 & 3000 & $\mathrm{~W}$ & 5 \\
Cairngorms & Low & 45.1 & 250.8 & 2350 & $\mathrm{~W}$ & 25 \\
& High & 57.12 & 3.5 & 740 & $\mathrm{~N}$ & 2 \\
Caucasus & Low & 57.12 & 3.5 & 400 & $\mathrm{NW}$ & 5 \\
& High & 42.48 & 44.39 & 3000 & $\mathrm{NW}$ & 3 \\
Colorado & Low & 42.48 & 44.39 & 2100 & $\mathrm{NW}$ & 3 \\
& High & 40.2 & 254.6 & 3500 & $\mathrm{E}$ & 10 \\
Kluane & Low & 40.2 & 254.6 & 2930 & $\mathrm{NE}$ & 10 \\
& High & 60.53 & 221.88 & 1750 & $\mathrm{SSE}$ & 40 \\
Spain & Low & 60.53 & 221.88 & 900 & $\mathrm{SE}$ & 25 \\
& High & 37.13 & 3.41 & 3100 & $\mathrm{SW}$ & 30 \\
Sweden & Low & 37.13 & 3.41 & 2400 & $\mathrm{SW}$ & 15 \\
& High & 68.2 & 18.45 & 1100 & $\mathrm{NW}$ & 20 \\
& Low & 68.2 & 18.45 & 580 & $\mathrm{~N}$ & 10 \\
\hline
\end{tabular}

$\dagger$ Above sea level.

2003), and there were attempts to analyze the importance of positive interactions for species diversity in stressful environments (Brewer et al. 1997, Hacker and Gaines 1997). Yet another line of research indicates that community diversity, per se, drives important ecosystem functions (Tilman et al. 2001, Loreau et al. 2002). Finally, local spatial patterns appear to correlate with the directions and strengths of plant interactions, lending insight into important processes such as nursing effect, niche limitation, and range contraction (Fonteyn and Mahall 1981, Bertness and Hacker 1994, Gotelli 2000, Choler et al. 2001, Wilson and Roxburgh 2001, Tirado and Pugnaire 2003).

Piecemeal examination of community patterns, processes, and properties has yielded invaluable information; however, whether or not the fundamental aspects of communities-productivity, diversity, interactions, spatial patterns, and abiotic drivers-relate to each other in some general way remains poorly understood. Here, we explore these relationships over large geographic scales in an effort to demonstrate how structure and function may be linked in communities. Based upon the common assumption that process relates to or even generates pattern, we tested correlative links among climate, standing biomass, experimentally derived plant interactions, spatial patterns, and species richness in 18 plant communities in nine Northern Hemisphere high-mountain systems.

\section{Methods}

We collected data at nine locations in West-Eurasian and North-American mountain systems (the Brooks Range of Alaska, the Alps of eastern France, the Absaroka Mountains [Beartooth Mountains] of Montana [USA], the Caucasus Mountains in Georgia, the Cairngorms of Scotland, the central Rocky Mountains of
Colorado, the Kluane Mountains in the western Yukon, the Sierra Nevada in Spain, and the Abisko Mountains in Sweden). We chose two study sites in each of these nine locations (Table 1). At each location one site was placed in subalpine vegetation and the other was placed from $300 \mathrm{~m}$ (Cairngorms) to $900 \mathrm{~m}$ (the Caucasus) higher in alpine vegetation.

Environmental conditions at these sites were characterized by data collected from nearby meteorological stations. We analyzed climate variables using principalcomponents analysis based on correlation-matrix eigenvalues.

We assessed standing mass by vegetation "volume" (the product of its projective cover [percent cover] and height [in centimeters]), and used this measure as a surrogate for productivity.

To quantify plant-plant interactions at the 18 sites we conducted removal experiments that are described elsewhere (Choler et al. 2001, Callaway et al. 2002). Plant interactions were calibrated using the relative interaction index (RII; Armas et al. 2004). This index represents neighbor effects as a continuum from competitive to facilitative, and is calculated as

$$
\mathrm{RII}=(C-T) /(C+T)
$$

where $T$ and $C$ correspond, respectively, to isolated (without neighbors) and control (with neighbors) individuals. The values between 0 and 1 indicate positive neighbor interactions (facilitation) and values between 0 and -1 indicate negative neighbor interactions (competition). At most sites, manipulations dealt with 5 native species (although in Sweden 3 and 5 species at low and high sites, respectively; in the Alps 10 species at both sites; in the Caucasus 7 and 5 species) for a total of 99 species. There were 12 replicates. Target species were chosen to represent a range of relative 
abundances. However, several dominant species were not used as targets in the experiments because discrete individuals were too difficult to find for these species.

At each of our 18 sites we also recorded the presence/ absence of all vascular species in 300 randomly placed, $10 \times 10 \mathrm{~cm}$ quadrats. The total area sampled varied in size $\left(25-50 \mathrm{~m}^{2}\right)$, but each sampling location was selected adjacent to experimental plots to control for topography and general species composition. To quantify spatial relationships among species, the observed variance in species number per quadrat can be compared to the variance expected from a random distribution of species (Schluter 1984, Palmer 1987, Gotelli 2000), using either the ratio or the difference of variances. The variance ratio (RV) has been used to describe spatial relationships in many different types of communities (Schluter 1984, Palmer 1987, Gotelli 2000, Wilson et al. 2000). The difference between variances, however, is more explicitly related to covariance because

$$
V_{\mathrm{obs}}=\sum \mathrm{var}+2 \sum \mathrm{cov}
$$

where $\Sigma$ var is the sum of variances of each species frequencies, and $\Sigma$ cov is net covariance, or the sum of covariance values obtained for all possible pairs of species in a given matrix. When net covariance is zero according to the null model, then the expected variance becomes merely the sum of variance of each species' frequencies (Palmer 1987); hence, the difference between the observed and expected variances actually measures net covariance: $\Sigma$ cov $=\left(V_{\text {obs }}-V_{\text {exp }}\right) / 2$. We selected covariance for our measurements of spatial pattern because it is symmetric around zero (unlike RV, which is constrained to values of zero and above), and because the interpretation of covariance is more straightforward (Wagner 2003). We calculated the observed and expected variances from the community matrices and used the equation above to calculate net spatial covariance.

We characterized diversity by richness, or the total number of species found in small quadrats. Richness is a primary measure of diversity, and the most recommended one for multi-scale comparisons (Kluth and Bruelheide 2004).

We used principles of path analysis (Shipley 1997) to examine relationships among data on temperature, precipitation, vegetation volume, plant-plant interactions, spatial patterns, and species richness. We used stepwise linear regression and best-subset regression models to define the path structure. However, we did not try to transform curvilinear cases into linear because it was related to sign change that indicated the direction of processes (e.g., negative vs. positive values of RII or spatial covariance [see above]). Consequently, for more accurate analysis of the curvilinear cases we used residuals of linear regression, then calculated second-order polynomial regressions (quadratic equa- tions), and tested dependences among all possible pairs of variables.

For statistical analyses we used the package Statistix 8 (Analytical Software, Tallahassee, Florida, USA).

\section{RESUlts}

Three principal components (PC) accounted for $93.3 \%$ of between-site variance in climate. The first component was responsible for $43.2 \%$ of variance and was related to summer temperature maxima. The mean June maximum temperature was the most highly correlated maxima with $\mathrm{PC}$ axis $1(R=-0.884, P<$ $0.0001)$. The second component ( $28 \%$ of variance) was related to summer temperature minima, with the mean July maximum temperature the strongest single minima ( $R=-0.9342, P<0.0001)$. Finally, the third component $(22.2 \%$ of variance) was related to the mean precipitation from May to August $(R=-0.9521, P<$ $0.0001)$. Correlations among these climate variables were insignificant (Table 2), and therefore we used them in path analysis.

We initiated the path analysis based on the correlation matrix for all variables (Table 2). Of 21 correlative links, only five were statistically significant. This lack of strength was apparently due to the nonlinear nature of these relationships, which were unsuitable for analysis by linear regression. Indeed, analysis of residuals found that most relations were nonlinear, and that some key relationships were not detected by linear correlations (noted in Table 2). Therefore we could not develop a full path analysis and construct structural equation models. Consequently, we performed partial path analysis with near-linear relationships and then combined this approach with bivariate quadratic regression analyses of the nonlinear cases.

The resulting path structure with coefficients of determination calculated from quadratic regressions is presented in Fig. 1. Different climate variables had strong relationships with specific characteristics of the plant communities. The volume of vegetation (productivity surrogate) was 100 times higher at the highest mean June maximum temperature $\left(25^{\circ} \mathrm{C}\right)$ than at the lowest mean June maximum temperature $\left(4^{\circ} \mathrm{C}\right)$. An unusual nonlinear relationship was detected among the mean July minimum temperature, the strength and direction of plant interactions, and spatial relationships among species. Interspecific facilitation and aggregated spatial patterns predominated at sites with low and high temperature minima, whereas strong competitive interactions and overdispersed spatial relationships were the highest at sites with intermediate temperature minima (Fig. 2A). Community richness was not correlated with site temperature, but richness increased from 10 species to 61 species with an increase in growing season precipitation from $<100 \mathrm{~mm}$ to $500 \mathrm{~mm}$.

There were other significant relationships among community attributes (Fig. 1). The strength and direction of plant interactions and the spatial relationships 
TABLE 2. Correlation matrix of climate and vegetation variables; main entries are $r$, with $P$ values below in parentheses.

\begin{tabular}{ccccccc}
\hline \hline Variable & $\mathrm{T} 6_{\max }$ & $\mathrm{T} 7_{\min }$ & Pr. & Vol. & RII & Cov. \\
\hline $\mathrm{T} 7_{\min }$ & -0.1417 & & & & & \\
& $(0.5749)$ & & & & & \\
Pr. & 0.1127 & -0.2015 & & & & \\
& $(0.6561)$ & $(0.4228)$ & & & & \\
Vol. & 0.6819 & 0.2734 & 0.1634 & & & \\
& $(0.0018)$ & $(0.2723)$ & $(0.5171)$ & & & \\
RII & -0.4319 & $-0.3505 \dagger$ & -0.2396 & $\mathbf{- 0 . 7 8 7 1}$ & & \\
& $(0.0735)$ & $(0.1538)$ & $(0.3383)$ & $\mathbf{( 0 . 0 0 0 1 )}$ & $\mathbf{0 . 7 3 1 7}$ & \\
Cov. & -0.2368 & $-0.2009 \dagger$ & -0.2579 & $\mathbf{- 0 . 6 3 5 9}$ & $\mathbf{( 0 . 0 0 0 6 )}$ & \\
& $(0.3441)$ & $(0.4240)$ & $(0.3015)$ & $\mathbf{( 0 . 0 0 4 6 )}$ & $\mathbf{( 0 . 0 3 5 )}$ \\
$S$ & 0.2782 & -0.1736 & $\mathbf{0 . 6 3 1 4}$ & 0.3655 & -0.3233 & $-0.4590 \dagger$ \\
& $(0.2637)$ & $(0.4909)$ & $\mathbf{( 0 . 0 0 5 0})$ & $(0.1359)$ & $(0.1906)$ & $(0.0553)$ \\
\hline
\end{tabular}

Notes: Vol. is vegetation volume (percent cover $\times$ height $\mathrm{cm}$ ); RII is relative interaction index (for neighbors); Cov. is the net spatial covariance; $S$ is species richness; $\mathrm{T}_{\max }$ is mean maximum June temperature $\left({ }^{\circ} \mathrm{C}\right) ; \mathrm{T} 7_{\min }$ is mean minimum July temperature $\left({ }^{\circ} \mathrm{C}\right)$; $\operatorname{Pr}$. is mean precipitation $(\mathrm{mm})$ during the growing season (May-August); $P$ is the significance level; boldface entries are statistically significant $(P<0.05)$.

$\dagger$ Nonlinear relationship.

among plant species were linearly correlated with vegetation volume. Competition was the most intense at sites with high biomass, whereas facilitation was more intense in communities with low biomass. Similarly, high-biomass communities were characterized by overdispersed spatial patterns among species and low-biomass communities demonstrated aggregated spatial patterns. As might be expected from the biomass relationships, spatial aggregation was strongest where facilitative interactions predominated, and spatial overdispersion was strongest where competition predominated.

Spatial pattern was related to species richness. The deviation of net spatial covariance from zero toward either negative or positive values was accompanied by an increase in species richness. In other words, species richness was lowest at sites with random spatial distributions among species, but increased when spatial relationships among species shifted to either aggregated or over-dispersed patterns (Fig. 2B). Removal of the two left-hand-side outliers did not affect the observed relation. Despite the relationship between com-

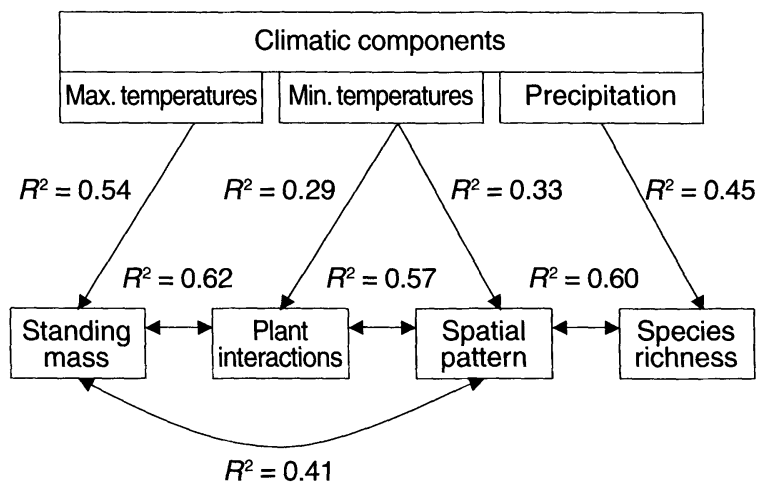

FIG. 1. Path analysis of relationships among climate variables and for vegetation characteristics. munity richness and spatial pattern, community richness did not correlate with the strength and direction of plant interactions $\left(R^{2}=0.1049, P=0.1897\right.$, not shown). Finally, there was a weak linear relationship between species richness and vegetation volume $\left(R^{2}=\right.$ $0.1369, P=0.1415$, not shown).

\section{Discussion}

The observed links among climate, community spatial patterns, and community processes can be summarized as follows: (1) sites with milder climates (e.g., low-elevation sites of the Caucasus and the Alps) were relatively more productive, and at these sites competition corresponded with over-dispersed distribution of plants, reduced intraspecific patchiness and, in turn, increased local richness; (2) sites with colder climates (e.g., high-elevation sites of the Alps and the Beartooth Mountains) were relatively less productive, and at these sites many species seemed to benefit from neighbor protection corresponding to an aggregated distribution of plants with also increased richness; (3) communities occurring at intermediate temperatures (e.g., the highelevation site in the Cairngorms, the low-elevation site in the Brooks Range) demonstrated intermediate productivity, weak interactions, random distributions of plants, and species richness lower than at relatively colder or warmer sites.

Overall, these findings support the hypotheses that abiotic stress and productivity are drivers of the nature and strength of species interactions (Bertness and Callaway 1994, Brooker and Callaghan 1998, Bruno et al. 2003), and that these interactions in turn drive spatial pattern (Haase 2001, Wilson and Roxburgh 2001). However, to our knowledge the strong relationship we observed between interspecific spatial pattern and species richness is unique in the literature. Species richness was lowest in sites with random spatial distributions but increased with either aggregated or over-dis- 
FIG. 2. Nonlinear relations among climate variables and plant community properties. (A) Concave dependence of species interactions and spatial pattern on mean minimum July temperature. Facilitation and aggregated distribution are observed at extremes, while at intermediate minima, species interactions are competitive, and plant distribution is overdispersed. (B) RII $(\checkmark)$ is the relative interaction index (for neighbors); net covariance ( $\square$ ) is the sum of covariance values obtained for all possible pairs of species in the community matrices. Species richness depends on departure of the spatial pattern from random distribution. Both aggregation and overdispersion coincide with higher richness.
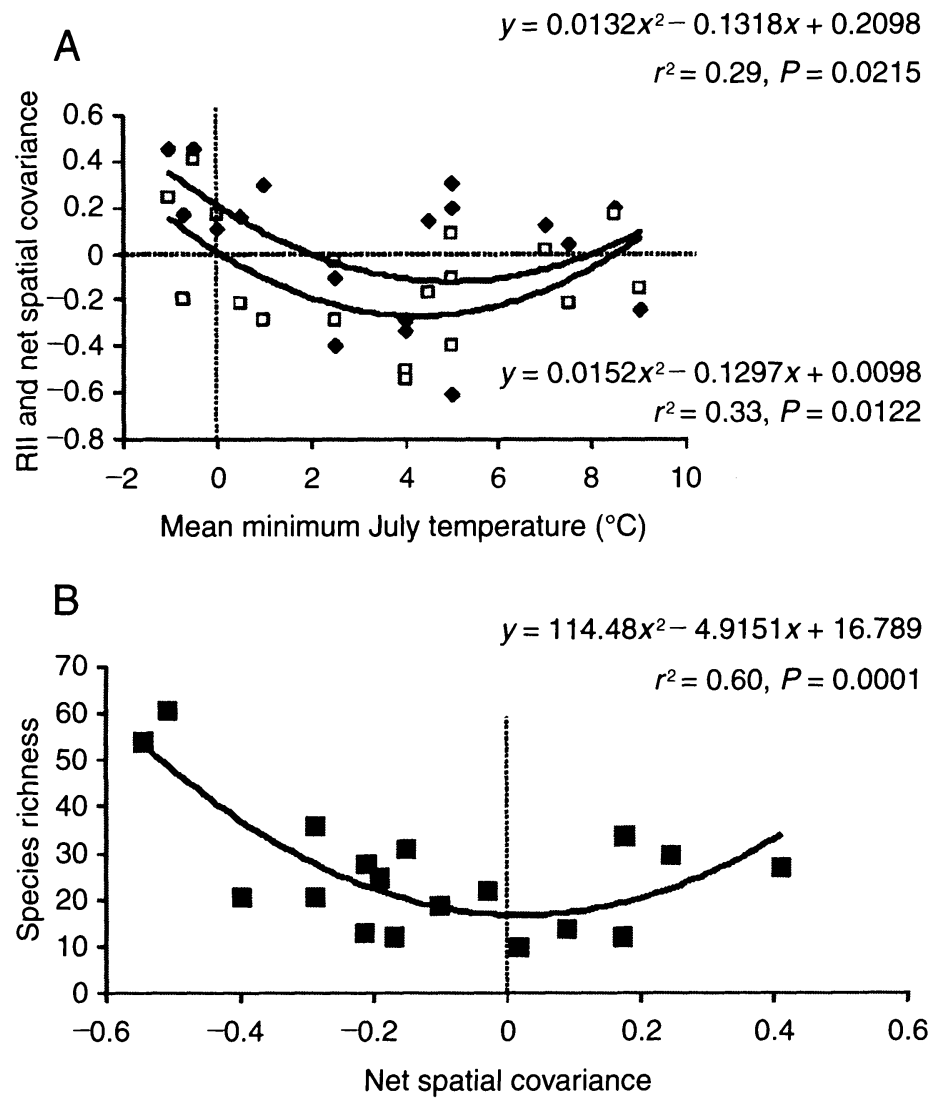

persed patterns. This finding corresponds surprisingly well with a recent individual-based simulation model of how positive and negative species interactions vary across environmental gradients (Travis et al. 2004). In particular, their patch-occupancy model predicts that groups of mutualists tend to occur in environmental conditions beyond the physical limits of non-mutualists. Most interestingly, Travis et al.'s model predicts a transitional band between mutually interacting groups and competing groups. This transitional band has a low population density and zero net interactions resulting from the balance of positive and negative effects.

These coinciding empirical and theoretical findings emphasize the importance of studying community structure and function over broad environmental gradients, but also provide a unique perspective on the possible significance of spatial relations. We suspect that over-dispersed spatial distribution in competitive communities is due to niche separation between plant functional groups in space (Wilson and Roxburgh 2001), which may allow more species to co-occur in a community. At the same time, aggregated pattern in facilitative communities must be due to niche construction by benefactor species (Odling-Smee et al. 1996), which modifies habitats and allows beneficiary species to co-occur (Brewer et al. 1997, Hacker and Gaines 1997, Bruno et al. 2003). In intermediate communities, however, these processes may cancel out each other, thus impeding development of richness-enhancing spatial niches.

The strong relationship between spatial arrangements among species and community diversity may be important for understanding how diversity may affect ecosystem function. The effects of diversity on ecosystem functions in the recent proliferation of diversity-function studies are primarily derived from relatively short-term experiments with recently established plant communities, in which measures are often taken to homogenize spatial structure (Loreau et al. 2001, 2002, Hector et al. 2002, Loreau and Holt 2004). Even without such homogenization of spatial structure, the relatively short duration of these experiments may not allow communities to develop spatial structure. By not developing natural spatial patterns, the importance of diversity in natural systems may be difficult to resolve.

Importantly, our results show that different aspects of climate may influence specific processes and patterns in plant communities. For example, it is likely that June mean maximum temperature represents general growing conditions in alpine and subalpine environments, with more favorable warm temperatures increasing biomass accumulation. On the other hand, July mean minimum temperature, which was highly correlated with plant interaction strength and spatial pattern, may reflect the intensity of abiotic stress experienced by alpine communities. However, the nature of the relation- 
ship between total growing-season precipitation and species richness is much harder to explain. These specific effects of climate components on vegetation may be important for predicting the effects of future climate change (Hallett et al. 2004), and consequently warrant more detailed investigation in other communities.

In our study, we followed two lines of analysis and synthesis. First, we worked over broad geographical gradients. Second, we studied links among a suite of different community attributes. Consequently, despite our empirical approach, our research may have value as a general model for seeking connections among disparate aspects of community ecology.

\section{ACKNOWLEDGMENTS}

We are grateful to C. Armas, E. Aschehoug, T. Callaghan, B. Cook, L. Paolini, L. Khetsuriani, D. Kikodze, B. Newingham, and R. Tirado for their assistance and valuable discussions, and to the Abisko Naturvetenskapliga Station (Swedish Royal Academy for Sciences), Civilian Research and Development Foundation (USA), MCYT (Spain), the National Geographic Society, Andrew W. Mellon Foundation, National Science Foundation (USA), and the National Center for Ecological Analysis and Synthesis (USA) for their generous support.

\section{Literature Cited}

Armas, C., R. Ordiales, and F. I. Pugnaire. 2004. Measuring plant interactions: a new comparative index. Ecology 85: 2682-2686.

Bertness, M., and R. M. Callaway. 1994. Positive interactions in communities. Trends in Ecology and Evolution 9:191193.

Bertness, M. D., and S. D. Hacker. 1994. Physical stress and positive associations among marsh plants. American Naturalist 144:363-372.

Brewer, J. S., J. M. Levine, and M. D. Bertness. 1997. Effects of biomass removal and elevation on species richness in a New England salt marsh. Oikos 80:333-341.

Brooker, R., and T. V. Callaghan. 1998. The balance between positive and negative interactions and its relationship to environmental gradients: a model. Oikos 81:196-207.

Bruno, J. F., J. J. Stachowicz, and M. D. Bertness. 2003. Inclusion of facilitation into ecological theory. Trends in Ecology and Evolution 18:119-125.

Callaway, R. M., R. W. Brooker, P. Choler, Z. Kikvidze, C. J. Lortie, R. Michalet, L. Paolini, F. I. Pugnaire, B. J. Cook, E. T. Aschehoug, C. Armas, and B. Newingham. 2002. Positive interactions among alpine plants increase with stress. Nature 417:844-848.

Choler, P., R. Michalet, and R. M. Callaway. 2001. Facilitation and competition on gradients in alpine plant communities. Ecology 82:3295-3308.

Fonteyn, P. J. and B. E. Mahall. 1981. An experimental analysis of structure in a desert plant community. Journal of Ecology 69:883-896.

Gaston, K. J., and T. M. Blackburn. 2000. Pattern and process in macroecology. Blackwell Science, Oxford, UK.

Gotelli, N. J. 2000. Null model analysis of species co-occurrence patterns. Ecology 81:2606-2621.

Grime, P. J. 2001. Plant strategies, vegetation processes, and ecosystem properties. Second edition. John Wiley and Sons, Chichester, UK.

Haase, P. 2001. Can isotropy vs. anisotropy in the spatial association of plant species reveal physical $v s$. biotic facilitation? Journal of Vegetation Science 12:127-136.
Hacker, S. D., and S. Gaines. 1997. Some implications of direct positive interactions for community species diversity. Ecology 78:1990-2003.

Hallett, T. B., T. Coulson, J. G. Pilkington, T. H. CluttonBrock, J. M. Pemberton, and B. T. Grenfell. 2004. Why large-scale climate indices seem to predict ecological processes better than local weather. Nature 430:71-75.

Hector, A., E. Bazeley-White, M. Loreau, S. Otway, and B. Schmid. 2002. Overyielding in grassland communities: testing the sampling effect hypothesis with replicated biodiversity experiments. Ecology Letters 5:502-511.

Kluth, C., and H. Bruelheide. 2004. Using standardized sampling designs from population ecology to assess biodiversity patterns of therophyte vegetation across scales. Journal of Biogeography 31:363-377.

Lawton, J. H. 2000. Community ecology in a changing world. Ecology Institute, Oldendorf/Luhe, Germany.

Loreau, M., and R. D. Holt. 2004. Spatial flows and the regulation of ecosystems. American Naturalist 163:606615 .

Loreau, M., S. Naeem, and P. Inchausti, editors. 2002. Biodiversity and ecosystem functioning: synthesis and perspectives. Oxford University Press, Oxford, UK.

Loreau, M., S. Naeem, P. Inchausti, J. Bengtsson, J. P. Grime, A. Hector, D. U. Hooper, M. A. Huston, D. Raffaelli, B. Schmid, D. Tilman, and D. A. Wardle. 2001. Ecologybiodiversity and ecosystem functioning: current knowledge and future challenges. Science 294:804-808.

Lortie, C. J., R. W. Brooker, P. Choler, Z. Kikvidze, R. Michalet, F. I. Pugnaire, and R. M. Callaway. 2004. Rethinking plant community theory. Oikos 107:433-438.

McKane, R. B., L. C. Johnson, G. R. Shaver, K. J. Nadelhoffer, E. B. Rastetter, B. Fry, A. E. Giblin, K. Kiellandk, B. L. Kwiatkowski, J. A. Laundre, and G. Murray. 2002. Resource-based niches provide a basis for plant species diversity and dominance in arctic tundra. Nature 415:6871.

Odling-Smee, F. J., K. N. Laland, and M. W. Feldman. 1996. Niche construction. American Naturalist 147:641-648.

Palmer, M. W. 1987. Variability in species richness within Minnesota oldfields: a use of the variance test. Vegetatio 70:61-64.

Schluter, D. 1984. A variance test for detecting species associations, with some example applications. Ecology 65: 998-1005.

Shipley, B. 1997. Exploratory path analysis with application in ecology and evolution. American Naturalist 149:11131138.

Tilman, D., P. B. Reich, J. Knops, D. Wedin, T. Mielke, and C. Lehman. 2001. Diversity and productivity in a longterm grassland experiment. Science 294:843-845.

Tirado, R., and F. I. Pugnaire. 2003. Shrub spatial aggregation and consequences for reproductive effort. Oecologia 136: 296-301.

Travis, J. M. J., R. W. Brooker, and C. Dytham. 2004. The interplay of positive and negative species interactions across an environmental gradient: insights from an individual-based simulation model. Proceedings of the Royal Society of London, Series B (Suppl.: Biology Letters). 〈http://www.journals.royalsoc.ac.uk $\rangle$.

Wagner, H. H. 2003. Spatial covariance in plant communities: integrating ordination, geostatistics, and variance testing. Ecology 84:1045-1057.

Wilson, J. B., and S. H. Roxburgh. 2001. Intrinsic guild structure: determination from competition experiments. Oikos 92:189-192.

Wilson, J. B., J. B. Steel, J. E. Newman, and W. McG. King. 2000. Quantitative aspects of community structure examined in a semi-arid grassland. Journal of Ecology 88: 749-756. 